\title{
Medication prescribing pattern in primary care in Riyadh city, Saudi Arabia
}

\author{
Y. Neyaz, ${ }^{1}$ T. Khoja, ${ }^{2}$ N.A. Qureshi, ${ }^{3}$ M.A. Magzoub, ${ }^{4}$ A. Haycox ${ }^{5}$ and T. Walley ${ }^{6}$
}

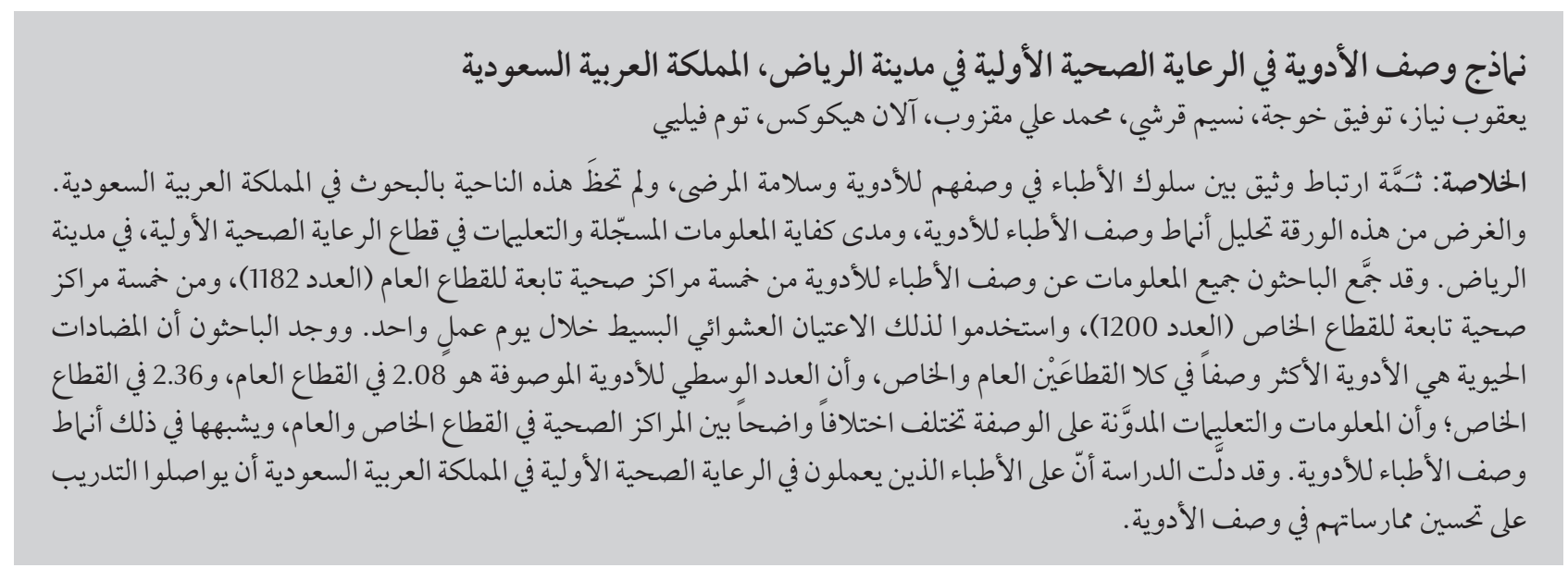

ABSTRACT Physicians' prescribing behaviour is closely linked with patient safety and this area is poorly researched in Saudi Arabia. The objective of this study was to analyse physicians' prescribing patterns and the adequacy of noted information in the primary health care sector in Riyadh city. All medication prescriptions from 5 public $(n=1182)$ and 5 private $(n=1200)$ health centres were collected by simple random sampling during 1 working day. Antibiotics were the most commonly prescribed drugs in both sectors. The mean number of drugs per prescription was 2.08 and 2.36 in the public and private sectors respectively. Information and instructions noted on prescriptions varied considerably between private and public health centres. Similarly the medication prescribing pattern differed across the 2 health settings. Primary care physicians in Saudi Arabia need continuing training to improve their prescribing practices.

\section{Mode de prescription de médicament en soins de santé primaires à Riyadh (Arabie saoudite).}

RÉSUMÉ Le comportement prescripteur des médecins est étroitement lié à la sécurité du patient et ce domaine est peu étudié en Arabie saoudite. L'objectif de la présente étude était d'analyser le mode de prescription des médecins et d'évaluer la pertinence des données rédigées dans le secteur des soins de santé primaires à Riyadh. Toutes les prescriptions de médicament issues de cinq centres de santé publics $(n=1182)$ et de cinq centres de santé privés $(n=1200)$ ont été collectées par échantillonnage aléatoire simple au cours d'une journée de travail. Les antibiotiques étaient les médicaments les plus fréquemment prescrits dans les deux secteurs. Le nombre moyen de médicaments par prescription était de 2,08 dans le secteur public et de 2,36 dans le secteur privé. Les informations et les instructions notées sur les prescriptions variaient considérablement entre les centres de santé privés et les centres de santé publics. Parallèlement, le mode de prescription de médicament différait entre les deux secteurs sanitaires. Les médecins de soins de santé primaires en Arabie saoudite ont besoin d'une formation continue pour améliorer leurs pratiques de prescription.

${ }^{1}$ General Directorate for Quality Development; ${ }^{3}$ General Administration for Mental Health and Social Services and Medical Research, Ministry of Health, Riyadh, Saudi Arabia (Correspondence to N.A. Qureshi: qureshinaseem@live.com).

${ }^{2}$ Cooperation Council for the Arab States of the Gulf, Riyadh, Saudi Arabia.

${ }^{4}$ Department of Medical Education, College of Medicine, King Abdulaziz Medical City, Riyadh, Saudi Arabia.

${ }^{5}$ School of Management; ${ }^{6}$ Department of Internal Medicine, University of Liverpool, Liverpool, United Kingdom. 


\section{Introduction}

Medication prescribing is one of the most fundamental activities practised by physicians and the subject has been reviewed in more detail in the literature reviews accompanying this series of papers [1-3].

The goal of the study reported here was to provide evidence to inform the debate about prescribing safety in Saudi Arabia. A key concern was the question whether even the most basic aspects of safe prescribing are followed: specifically the writing of the prescription in accordance with health service regulations. According to Ministry of Health regulations, physicians in both the public- and privately-funded health care sectors are required to ensure that all items of the patient clinical management forms are completed correctly. In essence the clinical management form represents the prescription form issued to patients by the physician, although its format varies slightly between the 2 sectors. Common parameters for the 2 types of form include: patient's name and age, physician's name, diagnosis and treatment and vital signs. The way in which the diagnosis and treatment elements of the consultation are recorded is much more specific on the public sector forms. In addition, physicians in public-funded clinics are constrained to the Saudi primary health care (PHC) formulary, while privately-funded primary care doctors are not.

This study, the first of its kind in Saudi Arabia, aimed to analyse and compare physicians' medication prescribing pattern and the adequacy of information noted in prescription forms in private and public $\mathrm{PHC}$ centres in Riyadh city, Saudi Arabia.

\section{Methods}

The study was a cross-sectional survey of medication prescriptions from public and private PHC centres in Riyadh.
Permission to conduct the study was obtained from the relevant public and private health authorities.

\section{Setting and sample}

Riyadh city is served by almost 120 PHC centres distributed across 5 health sectors, i.e. $24 \mathrm{PHCs}$ per health sector. For this study, we randomly selected 1 public and 1 private $\mathrm{PHC}$ from each health sector. Thus 5 government centres and 5 private $\mathrm{PHC}$ centres participated in the study. These centres were typical of those across the city, offering services to a large population who are fairly representative of the Riyadh region.

The survey in all the centres was conducted on 1 single full working day in January 2002 with 2 shifts in each centre. The day was chosen from the 5 working days, again by a similar simple random sampling method. The patients' clinical management forms were examined and all prescriptions for medications from all consultations on the day of the study were analysed, 1182 from public and 1200 from private $\mathrm{PHC}$ centres. All prescription data were collected on the same date to ensure that seasonal or daily fluctuations in prescribing behaviour did not affect the pattern of prescriptions collected. The aim was to give a complete picture of comparative prescription patterns and to reflect accurately the range of typical consultations covering patients' age, sex, and morbidity, curative and preventive measures and various lengths of consultation times. In addition, we selected a day when specific $\mathrm{PHC}$ services such as vaccinations and follow-up of maternity cases were not delivered. Copies of all prescriptions were collected from each PHC centre and analysed in detail for completeness in each centre.

\section{Data collection and entry}

The prescription variables analysed in the study were the presence of: patient's file number, name, age, sex and nationality; diagnosis; number of drugs per prescription; date; and prescriber's name and signature with stamp. The legibility of the prescriptions were also evaluated from a sample of prescriptions written by 25 physicians: 3 evaluators (Y.N. and 2 pharmacists) reached a consensus about whether the prescription was clearly written or not. In addition the diagnosis recorded on the prescription and types of medication prescribed were noted. The drug-related variables were analysed by noting which of the following items were present on the prescriptions as instructions to the pharmacist: strength and dose of medication; frequency and duration of administration; and instructions about how to use it (i.e. when to use the drug, how many times to take it, whether before or after meals). These were analysed for the first 5 drugs on each prescription.

Data were entered by 2 graduate research assistants who received extensive training from 2 pharmacists prior to their involvement with the study. Before formal data entry began and to ensure consistency of data entry, each assistant first evaluated 10 records and discussed any points of disagreement. This was repeated until the research assistant achieved $97 \%$ concordance in recording the variables selected from both private and public sector records. Such a level of consistency was thought to be adequate for the purpose of this study. However, as an additional quality assurance measure, 10 prescriptions chosen at random were also checked against the records on the database. Again, consistency was at least $97 \%$ and considered satisfactory. Dual data entry was considered excessively expensive and was therefore not performed.

\section{Data analysis}

The data were entered in the computer using SPSS software program, version 10. Analysis was conducted following cleaning of the data and testing of its quality as above. Frequencies were computed for all variables under investigation. The mean number of drugs per prescription for both health sectors 
was computed by dividing the total number of drugs by the total number of prescriptions. Univariate analysis, chi-squared test, $t$-test and Z-test were conducted. These statistical tests were used for cross-tabulation, to analyse categorical and continuous variables and to analyse the differences in the rate of medication prescriptions between public and private $\mathrm{PHC}$ centres.

\section{Results}

\section{Basic information recorded on prescriptions}

The statistical analysis of the recorded variables of the prescriptions from the public and private health sectors revealed that the data were significantly better recorded in the public sector with regard to file number, patient's name, sex, nationality, diagnosis and doctor's signature $(P<0.05)$ (Table 1$)$. In contrast, the doctors' name and date of prescriptions were noted better in private than public prescriptions. Patient's age, vital signs and ICD-9 diagnostic code were only recorded in public $\mathrm{PHC}$ centres and therefore no comparison with the private sector could be undertaken.
The prescriptions were for a total of 2463 drugs in the public clinics and 2836 from the private clinics. Therefore a mean of 2.08 drugs [95\% confidence interval $(\mathrm{CI}):=2.00-2.17)]$ were prescribed per prescription in the public sector compared with 2.36 (95\% CI: $2.27-2.45)$ in the private sector. There was, therefore, a significantly higher rate of drugs prescribed per prescription in the private sector $(Z=4.56, P<0.001$, 95\% CI: 1.60-3.99). In the public sector, unlike the private health sector, no patient received a prescription for more than 4 drugs.

\section{Diagnoses recorded on prescriptions}

The most frequent diagnosis noted in public health prescriptions was upper respiratory tract infection (RTI) (51.2\% of prescriptions) whereas gastrointestinal disorders were the most frequent diagnosis in private health sector prescriptions (10.9\%). Full details of the distribution of diagnoses in both the public and private sectors are provided in Table 2.

\section{Drug-related information recorded on prescriptions}

An analysis of the drug-related information recorded on prescriptions is shown in Table 3 (drug 1 indicates item 1 in prescriptions with at least 1 item; drug 2 indicates item 2 in prescriptions with at least 2 items, etc).

The legibility of the prescriptions ranged from $72.8 \%$ to $93.2 \%$ for different items in the public sector and from $67.2 \%$ to $85.9 \%$ in the private sector.

The quality of instructions provided to the pharmacists was poor in both sectors. Depending on the item, the strength of the drug was noted for only $17.3 \%$ of prescriptions in the public sector and $20.0 \%$ in the private sector. Details of the drug dose were recorded in more items in private clinics (90.9\%-95.8\%) than in the public clinics $(76.3 \%-80.6 \%)$. Frequency of use of medication was also slightly better recorded in private than public clinics. Duration of drug use was recorded for less than half of most items in both public and private sectors. Instructions for use were rarely given: for only approximately $7 \%$ of items in public PHCs and 5\% in private clinics.

\section{Types of medications prescribed on prescriptions}

Table 4 provides details of the medications prescribed in both the public and private sectors. As many prescriptions

\begin{tabular}{|c|c|c|c|c|c|c|}
\hline \multirow[t]{2}{*}{ Information recorded } & \multicolumn{2}{|c|}{$\begin{array}{l}\text { Public PHC centres } \\
\qquad(n=1182)\end{array}$} & \multicolumn{2}{|c|}{$\begin{array}{l}\text { Private PHC centres } \\
\qquad(n=1200)\end{array}$} & \multirow[t]{2}{*}{$\chi^{2}$-value ${ }^{a}$} & \multirow[t]{2}{*}{$P$-value } \\
\hline & No. & $\%$ & No. & $\%$ & & \\
\hline Patient name & 1182 & 100.0 & 1175 & 97.9 & 24.9 & $<0.001$ \\
\hline Patient sex & 1182 & 100.0 & 531 & 44.3 & 92.3 & $<0.001$ \\
\hline Doctor signature & 1144 & 96.8 & 874 & 72.8 & 263.9 & $<0.001$ \\
\hline Diagnosis & 1076 & 91.0 & 156 & 13.0 & 145.1 & $<0.001$ \\
\hline Patient age & 1056 & 89.3 & $\mathrm{n} / \mathrm{r}$ & $\mathrm{n} / \mathrm{r}$ & - & - \\
\hline ICD-9 code & 956 & 80.9 & $\mathrm{n} / \mathrm{r}$ & - & - & - \\
\hline Patient nationality & 952 & 80.5 & 144 & 12.0 & 113.2 & $<0.001$ \\
\hline Date & 796 & 67.3 & 1111 & 92.6 & 237.6 & $<0.001$ \\
\hline File number & 716 & 60.6 & 623 & 51.9 & 18.4 & $<0.001$ \\
\hline Doctor name & 377 & 31.9 & 770 & 64.2 & 248.4 & $<0.001$ \\
\hline Clinical findings & 45 & 3.8 & $\mathrm{n} / \mathrm{r}$ & - & - & - \\
\hline
\end{tabular}

${ }^{a}$ Degrees of freedom $=1$.

$n=$ number of prescriptions analysed; $I C D-9=$ International classification of diseases (9th revision); $n / r=$ not recorded. 


\begin{tabular}{|c|c|c|c|c|c|c|}
\hline \multirow[t]{2}{*}{ Diagnosis recorded ${ }^{a}$} & \multicolumn{2}{|c|}{$\begin{array}{l}\text { Public PHC centres } \\
\qquad(n=1077)\end{array}$} & \multicolumn{2}{|c|}{$\begin{array}{l}\text { Private PHC centres } \\
\qquad(n=157)\end{array}$} & \multirow[t]{2}{*}{$\chi^{2}$-value ${ }^{e}$} & \multirow[t]{2}{*}{$P$-value } \\
\hline & No. & $\%$ & No. & $\%$ & & \\
\hline Upper respiratory tract infection & 551 & 51.2 & 15 & 9.6 & 94.9 & $<0.001$ \\
\hline Gastrointestinal disorder & 111 & 10.3 & 17 & 10.9 & 0.1 & NS \\
\hline Asthma & 53 & 4.9 & 11 & 7.1 & 1.3 & NS \\
\hline Diabetes mellitus & 50 & 4.6 & 10 & 6.4 & 0.9 & NS \\
\hline Urinary tract disorder & 43 & 3.9 & 16 & 10.3 & 11.7 & $<0.001$ \\
\hline Skin diseases & 37 & 3.4 & 10 & 6.4 & 3.3 & NS \\
\hline Eye diseases & 33 & 3.1 & 15 & 9.6 & 15.6 & $<0.001$ \\
\hline Poisoning ${ }^{\mathrm{b}}$ & 31 & 2.9 & 10 & 6.4 & 5.3 & 0.02 \\
\hline Musculoskeletal diseases & 27 & 2.5 & 15 & 9.6 & 20.9 & $<0.001$ \\
\hline Blood diseases $^{c}$ & 25 & 2.3 & 9 & 5.8 & 6.1 & 0.01 \\
\hline Cardiovascular system disorders & 23 & 2.1 & 8 & 5.1 & 4.9 & 0.02 \\
\hline Gynaecological disorders $^{d}$ & 18 & 1.7 & 8 & 5.1 & 7.9 & 0.005 \\
\hline Other & 74 & 6.9 & 12 & 7.7 & 0.2 & NS \\
\hline
\end{tabular}

${ }^{a}$ International classification of diseases (9th revision) categories; ${ }^{b}$ Plus trauma, accidents; ${ }^{c}$ Plus immune disorders, disorders include hypertension; ${ }^{d}$ Plus complications of pregnancy; ${ }^{e}$ Degrees of freedom $=1$.

$n=$ number of prescriptions analysed; $N S=$ not significant .

were for multiple drugs a total of 2463 prescribed drugs were analysed from public clinics and 2836 from private clinics. Antibiotics were the most commonly prescribe medications in both sectors and antidepressants the least. The statistical analysis revealed that the only significant differences between the 2 sectors were in the prescribing of antibiotics, corticosteroids, expectorants and cardiovascular drugs $(P<0.05)$. The rate of prescribing of antibiotics was higher in the public health sector, while corticosteroids, expectorants and cardiovascular drugs were significantly more likely to be prescribed on private prescriptions. However, with regard to other noted drugs, no significant differences were observed between the public and private health sector prescriptions.

\section{Discussion}

This survey has explored the medication prescribing pattern of physicians and the adequacy of recorded information on the prescriptions in patient records across the public and private health care sectors in Riyadh city. The quality of instructions provided to the pharmacists was poor in both sectors. Approximately 1 in 4 prescriptions from both the public and private sectors were unreadable. Drug strength was the least well recorded element, with over half of prescriptions omitting this item in both sectors. Appropriate dosage was recorded to a far greater extent in private (around 95\% of items) than in public prescriptions (80\%). Frequency of administration was also far better recorded in private prescriptions (around 92\% of items) than in public prescriptions (70\%). Approximately 50\% of items on prescriptions from both health sectors lacked information about the duration of treatment prescribed. The low level of accuracy of recording on prescriptions may be attributed to 2 main factors. First, some items that are only available in one strength, (such as creams, ointments or paracetamol) do not necessarily require specific instructions about strength. Secondly, the physician may have knowledge of the pharmacy to which the prescription will be taken, and therefore will be aware of the strength and type of drugs available.
Therefore, the physician may see no need to provide strength instructions to the pharmacist. Duration of use may not have been well recorded as many of the prescriptions were for antibiotics, which were probably to be used in standard regimens where the pharmacist would be expected to include the duration.

The instructions about the appropriate use of drugs also showed very poor rates of recording (less than 10\% for all items), which emphasizes the need for both public and private physicians to give more priority to completing the instructions for the prescribed medications. The need to maintain a high volume of consultations, particularly in privately-funded practices, may contribute to this. Physicians may also feel that providing this information is a role for the dispensing pharmacist.

Overall, public health care physicians tended to complete the prescriptions more fully than private health care doctors. The findings are partly consistent with national [4-7] and international trends $[8,9]$. The implications of this finding are administrative, legal and clinical. It is likely that these findings 


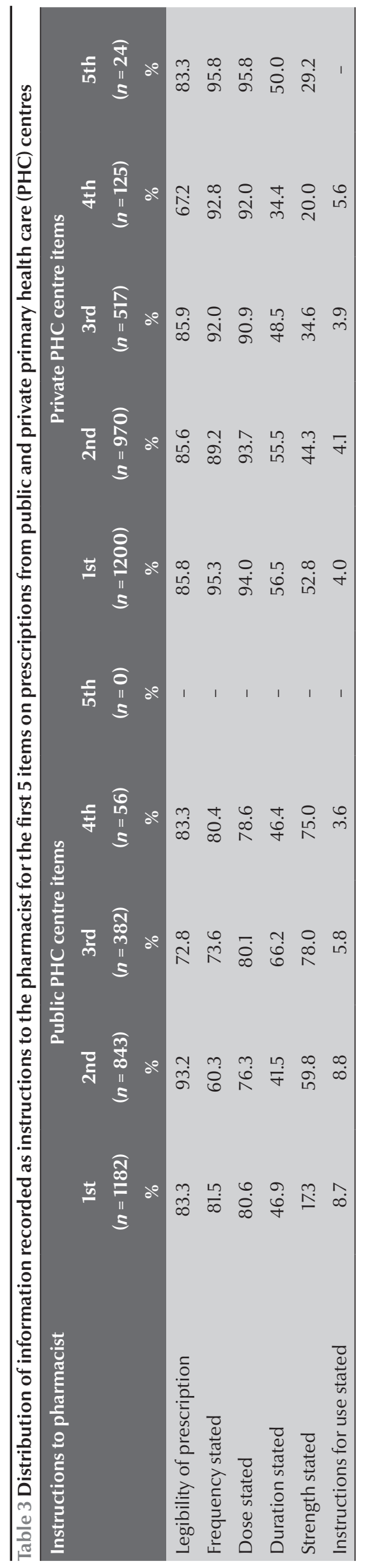

are explained by inadequate time and patient workload and low levels of staffing in the public sector. Other aspects of the system in Saudi Arabia may also contribute: for instance, the fact that there is no explicit monitoring of this aspect of the quality of prescribing means that its importance is not flagged up to doctors [10]. Therefore strategies need to be directed towards encouraging health providers to write complete prescriptions. The extent to which improved recording of prescribing information contributes to improved prescribing behaviour is open to debate. The international evidence, however, appears to indicate that better recording of such information can begin to contribute to patients' safety in a cost-effective way [11], e.g. avoiding tetracycline prescriptions in young children, documenting drug allergies, etc.

We found that $\mathrm{PHC}$ physicians often failed to record completely the information required to dispense prescriptions correctly and this again reflects the findings of other studies $[6,7,12]$. Such a failure may have importance adverse effects for patients [13]. For instance, failure to record the strength or dose of a drug may result in over- or underdosing. Such medication errors are preventable but require coordinated efforts by health providers in order to improve clinical outcomes and patient safety [14]. The real clinical significance of the omissions identified here is uncertain, and further study would be required.

Two major diagnostic groups were identified in prescriptions in this study: respiratory diseases especially in public clinics and abdominal diseases in both public and private health clinic patients. Other diagnoses such as urinary tract diseases, eye disorders, accidental poisonings, musculoskeletal disorders, haematological disorders, gynaecological diseases and cardiovascular diseases were more commonly recorded for private clinic patients. The explanation for these trends remains unclear and would require further study. A weakness of this study is that we have no gold standard for diagnosis but only the doctors' recorded diagnoses. We need to investigate whether the apparent differences represent differences in labelling or actual differences in morbidity between patients consulting in the 2 sectors. Our findings are partly consistent of with those of other studies suggesting that there may be differences in morbidity patterns between populations attending different types of health care facility perhaps due to differences in patients' social background $[6-8,15,16]$. It is also possible that the apparent differences are artefacts created by poor recording in the private sector. Analysis of the medication treatments prescribed suggests that this is the most likely explanation, since the pattern of drugs actually prescribed was very similar in both sectors.

This study revealed that antiinflammatory drugs, antipyretics, antiallergic and gastric acid blockers were heavily prescribed by physicians at both settings, which yet again partly corroborates the results of other studies [6-8,17-19]. Psychotropic drugs were prescribed the least frequently. Overall, this prescribing pattern is compatible with diagnostic patterns revealed in the 2 settings. Antibiotics, the most commonly prescribed drugs, were prescribed significantly more often in public than private clinics. Corticosteroids, expectorants and cardiovascular medications, however, were significantly more likely to be dispensed at private clinics. Unlike other research [20] our study did not analyse whether or not these medications were prescribed rationally. Repeat dispensing of antibiotics or other drugs [21] is allowed in Saudi Arabia but only if justified on clinical and scientific grounds. This prescribing 


\begin{tabular}{|c|c|c|c|c|c|c|}
\hline \multirow[t]{2}{*}{ Type of medication prescribed } & \multicolumn{2}{|c|}{$\begin{array}{l}\text { Public PHC centres } \\
\qquad(n=2463)\end{array}$} & \multicolumn{2}{|c|}{$\begin{array}{l}\text { Private PHC centres } \\
\quad(n=2836)\end{array}$} & \multirow[t]{2}{*}{$x^{2}$-value ${ }^{a}$} & \multirow[t]{2}{*}{$P$-value } \\
\hline & No. & $\%$ & No. & $\%$ & & \\
\hline Antibiotic & 520 & 44.0 & 456 & 38.0 & 8.8 & 0.002 \\
\hline Anti-inflammatory & 175 & 14.8 & 167 & 13.9 & 0.52 & NS \\
\hline Antipyretic & 78 & 6.7 & 72 & 6.0 & 0.36 & NS \\
\hline Antiallergic & 73 & 6.2 & 71 & 5.9 & 0.07 & NS \\
\hline Vitamin/tonic & 62 & 5.3 & 64 & 5.3 & 0.01 & NS \\
\hline Gastric acid blocker & 63 & 5.3 & 59 & 4.8 & 0.21 & NS \\
\hline Bronchodilator & 47 & 4.0 & 46 & 3.7 & 0.03 & NS \\
\hline Antiemetic & 38 & 3.2 & 40 & 3.4 & 0.03 & NS \\
\hline Hypoglycaemic & 30 & 2.5 & 40 & 3.4 & 1.32 & NS \\
\hline Corticosteroid & 15 & 1.3 & 39 & 3.3 & 10.6 & 0.001 \\
\hline Antispasmodic & 32 & 2.7 & 35 & 2.9 & 0.10 & NS \\
\hline Expectorant & 10 & 0.9 & 30 & 2.3 & 9.9 & 0.001 \\
\hline Cardiovascular drug & 11 & 0.9 & 30 & 2.3 & 8.7 & 0.003 \\
\hline Antidepressant & 8 & 0.7 & 17 & 1.4 & 3.14 & NS \\
\hline Other & 20 & 1.7 & 34 & 2.8 & 3.50 & NS \\
\hline
\end{tabular}

${ }^{a}$ Degrees offreedom $=1$.

$n=$ number of drugs prescribed; $N S=$ non-significant .

trend will further change in future as PHC centres are continuously taking on wider roles in managing chronic diseases, such as diabetes mellitus and coronary heart disease. However, antibiotics and corticosteroids should be prescribed carefully across both clinical settings by PHC physicians, as these medications are coupled with adverse effects including the risk of development of antibiotic-resistant strains of bacteria or osteoporosis [22-27].

Prescribing more than 1 drug was common in both public and private settings, although in the public sector, unlike the private health sector, no patient received a prescription for more than 4 drugs: the design of the public records system would have made this difficult. The findings of our research are consistent with other studies showing high rates of polypharmacy $[5-8,12]$. Although polytherapy is generally discouraged, it is justified in certain cases [28] and is perhaps inevitable in elderly populations who are often suffering from multiple chronic diseases [29]. In some cultures, however, such as Saudi Arabia the PHC physician is under considerable pressure from patients to reach a diagnosis and prescribe accordingly, possibly in the presence of a great deal of clinical uncertainty. This has quantitative, administrative and clinical implications. The prescription of drugs is often used to hasten the termination of the consultation $[4-6,8,30]$. As a result, many consultations in PHC in Saudi Arabia may result in inappropriate polypharmacy, which in turn raises a number of medical, social, economic and public safety concerns [7,9,31-34].

There are some limitations to the study; it represents a preliminary analysis in a complex area of prescribing. The 1-day prescription selection strategy can be expanded to improve the sample size. A larger sample size may help in achieving further statistical power for the results obtained. This research was conducted in Riyadh city and therefore the extent to which its findings can be generalized throughout Saudi Arabia is unknown. Future studies should explore prescribing trends in rural regions of Saudi Arabia. Computerized prescribing data collection systems would facilitate a more detailed analysis of prescribing. Computerization in primary care is in its infancy in Saudi Arabia, but the potential for undertaking large-scale analyses of prescribing in the future should not be underestimated.

To sumarize, in this study we found similar overall patterns of prescribing between the public and private health sectors with some variations in their diagnostic profiles. There were, however, important elements of prescribing that varied between the 2 sectors; in particular, polypharmacy was more common in the private sector. Several of the deficiencies in recording information on prescriptions could present a danger to patient safety. Measures are needed in Saudi Arabia to improve physicians' recording of complete information on prescriptions and to avoid injudicious use of polytherapy. 
1. Neyaz $\mathrm{Y}$ et al. Physicians' medication prescribing in primary care in Riyadh city, Saudi Arabia. Literature review, part 1: variations in drug prescribing. Eastern Mediterranean Health Journal, 2011, 17(2):126-131.

2. Khoja T. Physicians' medication prescribing in primary care in Riyadh city, Saudi Arabia. Literature review, part 2: rational prescribing. Eastern Mediterranean Health Journal, 2011, 17(2):132-139.

3. Qureshi NA. Physicians' medication prescribing in primary care in Riyadh city, Saudi Arabia. Literature review, part 3: prescribing errors. Eastern Mediterranean Health Journal, 2011, 17(2):140-148.

4. Al-Nasser AN. Prescribing patterns in primary healthcare in Saudi Arabia. Annals of Pharmacotherapy, 1991, 25:90-93.

5. Felimban FM. The prescribing practice of primary health care physicians in Riyadh city. Saudi Medical Journal, 1993, 14:335-338.

6. Khoja TA et al. Quality of prescribing at primary care centres in Saudi Arabia. Journal of Pharmacy Technology, 1996, 12:284-288.

7. Bawazir SA. Prescribing patterns of ambulatory care physicians in Saudi Arabia. Annals of Saudi Medicine, 1993, 13:172-177.

8. Gilleghan J. Prescribing in general practice. London: Royal College of General Practice, 1991:18-35 (Occasional Paper 54).

9. Dizwani AG et al. Morbidity patterns and prescribing habits in Harare primary care clinics. Family Practice, 1985, 2:82-85.

10. Peth HA Jr. Medication errors in the emergency department: a systems approach to minimizing risk. Emergency Medicine Clinics of North America, 2003, 21:141-158.

11. Schulmeister L. Ten simple strategies to prevent chemotherapy errors. Clinical Journal of Oncology Nursing, 2005, 9:201-205.

12. Al Khaja KA, Al-Ansari TM, Sequeira RP. An evaluation of prescribing errors in primary care in Bahrain. International Journal of Clinical Pharmacology and Therapeutics, 2005, 43:294-301.

13. Neville RG et al. A classification of prescription errors. Journal of the Royal College of General Practitioners, 1989, 39:110-112.

14. Adubofour KO et al. Strategies to reduce medication errors in ambulatory practice. Journal of the National Medical Association, 2004, 96:1558-1564.

15. Balbaid OM, Al-Dawood KM. Assessment of physicians' prescribing practices at Ministry of Health hospital in Jeddah city, Saudi Arabia. Saudi Medical Journal, 1998, 19:28-35.

16. Leistevuo J et al. Mikstra Collaborative Study Group. Prescription rates and diagnostic patterns are stable: a comparison of high-, medium- and low-prescribing primary care physicians treating community-acquired respiratory tract infections. Scandinavian Journal of Infectious Diseases, 2005, 37:465-470.

17. Bawazir SA. Prescribing pattern at community pharmacies in Saudi Arabia. International Pharmacy Journal, 1992, 6:222224.
18. Guglielmo L et al. Antimicrobial drug utilization in hospitals in Italy and other European countries. Infection, 1994; 3: S176-181.

19. Al-Faris EA, Al Taweel A. Audit of prescribing patterns in Saudi primary health care: what lessons can be learned? Annals of Saudi Medicine, 1999, 19:317-321.

20. Wong WC, Dickinson J, Chan C. Cough mixtures: rational or irrational prescribing in Hong Kong? Family Practice, 2005, 22:381-382.

21. De Smet PA, Dautzenberg M. Repeat prescribing: scale, problems and quality management in ambulatory care patients. Drugs, 2004, 64:1779-1800.

22. Little P et al. Reattendance and complications in a randomised trial of prescribing strategies for sore throat: the medicalising effect of prescribing antibiotics. British Medical Journal, 1997b, 315:350-352.

23. Little $\mathrm{P}$ et al. Open randomised trial of prescribing strategies in managing sore throat. British Medical Journal, 1997a, 314:722-727.

24. Arroll B, Kenealy T, Kerse N. Do delayed prescriptions reduce antibiotic use in respiratory tract infections? A systematic review. British Journal of General Practice, 2003, 53:871-877.

25. Dancer SJ. How antibiotics can make us sick: the less obvious adverse effects of antimicrobial chemotherapy. Lancet Infectious Diseases, 2004, 4:611-619.

26. Peterson LR, Dalhoff A. Towards targeted prescribing: will the cure for antimicrobial resistance be specific, directed therapy through improved diagnostic testing? Antimicrobial Agents and Chemotherapy, 2004, 53:902-905.

27. Ryan JG et al. Current management of corticosteroid-induced osteoporosis: variations in awareness and management. Irish Journal of Medical Science, 2004, 173:20-22.

28. Qureshi NA et al. Psychotropic drug prescriptions in primary care and general hospitals, in Saudi Arabia. Saudi Pharmaceutical Journal, 2001, 9:193-200.

29. Murray MD et al. A conceptual framework to study medication adherence in older adults. American Journal of Geriatric Pharmacotherapy, 2004, 2:36-43.

30. Bateman N. Approaches to rational prescribing. In: Hobbs $\mathrm{R}$, Bradley C, eds. Prescribing in primary care. Oxford, Oxford University Press, 1998:95-108.

31. Krishnaswamy K, Kumar BD, Radhaiah G. A drug survey-precepts and practices. European Journal of Clinical Pharmacology, 1985, 29:363-370.

32. Hogerzeil HV et al. Impact of an essential drugs programme on availability and rational use of drugs. Lancet, 1989, 1:141-142.

33. Taylor D. Prescribing in Europe-forces for change. British Medical Journal, 1992, 304:239-242.

34. Wilkie $\mathbf{P}$ et al. Prescribing at the hospital general practice interface. In: Hospital outpatient dispensing policies in England. British Medical Journal, 1992, 394:29-31. 